\title{
BMJ Open Direct costs of overdiagnosed asthma: a longitudinal, population-based cohort study in British Columbia, Canada
}

\author{
Bryan Ng, ${ }^{1}$ Mohsen Sadatsafavi, ${ }^{1,2}$ Abdollah Safari, ${ }^{1,2}$ J Mark FitzGerald, ${ }^{2}$ \\ Kate M Johnson (D) ${ }^{1}$
}

To cite: $\mathrm{Ng} \mathrm{B}$, Sadatsafavi M, Safari A, et al. Direct costs of overdiagnosed asthma: a longitudinal, populationbased cohort study in British Columbia, Canada. BMJ Open 2019;9:e031306. doi:10.1136/ bmjopen-2019-031306

- Prepublication history and additional material for this paper are available online. To view please visit the journal (http:// dx.doi.org/10.1136/bmjopen2019-031306).

Received 27 April 2019 Revised 25 September 2019 Accepted 07 October 2019

Check for updates

(C) Author(s) (or their employer(s)) 2019. Re-use permitted under CC BY-NC. No commercial re-use. See rights and permissions. Published by BMJ.

${ }^{1}$ Respiratory Evaluation Sciences Program, Collaboration for Outcomes Research and Evaluation, The University of British Columbia Faculty of Pharmaceutical Sciences, Vancouver, British Columbia, Canada

${ }^{2}$ Institute for Heart and Lung Health, The University of British Columbia Department of Medicine, Vancouver, British Columbia, Canada

Correspondence to

Ms Kate M Johnson

kate.johnson@alumni.ubc.ca

\section{ABSTRACT}

Objectives A current diagnosis of asthma cannot be objectively confirmed in many patients with physiciandiagnosed asthma. Estimates of resource use in overdiagnosed cases of asthma are necessary to measure the burden of overdiagnosis and to evaluate strategies to reduce this burden. We assessed differences in asthmarelated healthcare resource use between patients with a confirmed asthma diagnosis and those with asthma ruled out.

Design Population-based, prospective cohort study. Setting Participants were recruited through randomdigit dialling of both landlines and mobile phones in the province of British Columbia, Canada.

Participants We included 345 individuals $\geq 12$ years of age with a self-reported physician diagnosis of asthma. The diagnosis of asthma was reassessed at the end of 12 months of follow-up using a structured algorithm, which included a bronchodilator reversibility test, methacholine challenge test, and if necessary medication tapering and a second methacholine challenge test.

Primary and secondary outcome measures Selfreported annual asthma-related direct healthcare costs (2017 Canadian dollars), outpatient physician visits and medication use from the perspective of the Canadian healthcare system.

Results Asthma was ruled out in 86 (24.9\%) participants. The average annual asthma-related direct healthcare costs for participants with confirmed asthma were \$C497.9 (SD \$C677.9) and for participants with asthma ruled out, \$C307.7 (SD \$C424.1). In the adjusted analyses, a confirmed diagnosis was associated with higher direct healthcare costs (relative ratio $(\mathrm{RR})=1.60,95 \% \mathrm{Cl} 1.14$ to 2.22), increased rate of specialist visits $(\mathrm{RR}=2.41,95 \% \mathrm{Cl}$ 1.05 to 5.40$)$ and reliever medication use ( $R R=1.62$, $95 \% \mathrm{Cl} 1.09$ to 2.35 ), but not primary care physician visits $(p=0.10)$ or controller medication use $(p=0.11)$. Conclusions A quarter of individuals with a physician diagnosis of asthma did not have asthma after objective re-evaluation. These participants still consumed a significant amount of asthma-related healthcare resources. The population-level economic burden of asthma overdiagnosis could be substantial.

\section{INTRODUCTION}

Over 300 million people worldwide have been diagnosed with asthma. ${ }^{1}$ Patients with asthma

\section{Strengths and limitations of this study}

- Participants were recruited through random sampling of the general population in the province of British Columbia, Canada.

- Asthma diagnosis was confirmed or ruled out using a structured algorithm of guideline-recommended objective airway tests.

- Healthcare resource use was self-reported, and there is potential for recall bias to have reduced accuracy.

- We did not measure the indirect costs of asthma overdiagnosis, such as productivity loss, which may be substantial.

- The generalisability of the results may be limited by regional differences in medical costs and practices.

experience symptoms of wheezing, shortness of breath, chest tightness and cough. ${ }^{2}$ These symptoms, and periods of intensified disease activity referred to as exacerbations, or asthma lung attacks, ${ }^{3}$ impose a significant burden on healthcare resources and reduce patients' quality of life. ${ }^{4}$ A Canadian study estimated the excess direct medical costs of asthma at \$C1058 (2013 Canadian dollars) per person-year. ${ }^{5}$ The majority $(74 \%)$ of asthma-attributed costs were due to medication use. ${ }^{5}$

Multiple evidence-based guidelines recommend confirming a diagnosis of asthma with objective testing for reversible airflow limitation or increased airway hyperresponsiveness. ${ }^{2} 6$ Despite these recommendations, previous studies suggest that in the community, asthma is diagnosed solely based on symptom history in over half of the cases. $^{78}$ The underuse of spirometry has been documented in Canada, ${ }^{9} \mathrm{USA}^{10}$ and Europe. ${ }^{11}$ A recent population-based study found that one in three patients with physician-diagnosed asthma did not meet the guideline-recommended spirometric criteria for asthma diagnosis and could have their medications safely stopped. ${ }^{12}$ We refer to 
this group of patients as 'overdiagnosed'. ${ }^{13}$ These overdiagnosed patients are likely to be imposing costs on the healthcare system due to treatment for a condition that does not exist, and may be experiencing symptoms of an underlying illness that is not being treated. ${ }^{12}$ By some estimates, there are over 785000 patients with overdiagnosed asthma in Canada alone. ${ }^{14}$

In response to these findings, some authors have called for population-based screening or case finding to re-evaluate previous diagnoses of asthma. ${ }^{12}{ }^{14}$ Assessing the value of these programmes requires precise estimates of the burden of overdiagnosed asthma. To the best of our knowledge, estimates of the cost differences between overdiagnosed and confirmed cases of asthma currently do not exist. A previous study of the costs of overdiagnosed asthma was limited to assessing the potential asthma-related cost savings that a secondary screening programme could provide. ${ }^{14}$ Characterising the patterns of healthcare resource use among patients in whom asthma can be ruled out can help identify opportunities for re-evaluation and inform initiatives to improve asthma diagnosis in the community.

We used a longitudinal, population-based cohort of individuals with physician-diagnosed asthma to address this important evidence gap. Our primary objective was to compare total direct asthma-related healthcare costs in patients with a confirmed diagnosis of asthma versus patients in whom a diagnosis of asthma was ruled out using objective testing. Our secondary objectives were to characterise differences in healthcare resource use in terms of (1) the number of outpatient physician visits and (2) the type and amount of asthma medication use.

\section{METHODS}

\section{Study design and sample}

We used longitudinal data from the Economic Burden of Asthma study, which has been previously described. ${ }^{15} 16$ In summary, individuals with a self-reported physician diagnosis of asthma and at least one asthma-related healthcare encounter in the past 5 years were eligible. Participants were recruited through random-digit dialling of both landlines and mobile phones in the census subdivisions of Vancouver and Central Okanagan (populations of 603502 and 179839 in 2011, respectively) in British Columbia, Canada. ${ }^{17}$ Between 2010 and 2012, 618 participants were recruited, evaluated at baseline and followed for 12 months with visits at 3-month intervals. We included 345 participants who were $\geq 12$ years of age at baseline and successfully completed a bronchodilator reversibility or methacholine challenge test at the end of follow-up.

\section{Outcomes}

Participants reported their asthma-related primary care and specialist physician visits, hospitalisations, emergency department visits and current medication use at each study visit with a recall period of 3 months. The primary outcome was total asthma-related direct healthcare costs per patient over the 1-year follow-up period. Total direct healthcare costs comprised all outpatient and inpatient encounters and medication costs incurred by the patient. We determined the average proportion of total costs each category constituted. Per-patient costs were determined by multiplying self-reported resource use quantities by average unit costs of each resource. We used provincial physician billing data between 2008 and 2012 to determine the average unit cost of specialist versus primary care physician visits with asthma as the main diagnostic code. ${ }^{18}$ We determined the average unit cost of hospitalisation by multiplying the average cost of hospitalisation in the province for the corresponding fiscal year by the resource intensity weight assigned to hospital discharges with asthma as the main diagnostic code. ${ }^{19}$ Medication unit costs were determined by linking the drug identification numbers of participant-reported asthma medications to the Provincial Drug Master Plan database. ${ }^{20}$ Cost per dose was estimated using the lowest price equivalent of the medication. All costs were adjusted to 2017 Canadian dollars using the healthcare component of the Consumer Price Index. ${ }^{21}$ All analyses were conducted from the perspective of the Canadian healthcare system.

Secondary outcomes were the number of asthmarelated outpatient physician visits and the use of asthma medications. We did not evaluate asthma-related emergency department visits or hospitalisations as a separate outcome due to the low frequency of these events $(n=14)$. The number of outpatient physician visits over 1 year of follow-up was assessed separately by physician type (primary care or specialist). Medication use was captured using the questionnaire shown in online supplementary figure E1, and medications were classified into controller or reliever using a reference list (online supplementary table E1). In general, controller medications are those with antiinflammatory effects (namely, inhaled corticosteroids and leukotriene receptor antagonists), while reliever medications are those that are used on as-needed basis for temporary symptom relief (namely, short-acting beta agonists). Medication use was determined by calculating the medication possession ratio (MPR) separately for controller and reliever medications. MPR was calculated by dividing the total days in which participants reported taking medications of each type by the total follow-up time. It represents the proportion of days in which medications were available to the participant. ${ }^{22}$

\section{Exposure: objective confirmation of asthma}

Participants underwent an objective assessment of asthma at the final visit. The diagnostic algorithm for asthma is shown in figure 1 and consisted of both bronchodilator reversibility and methacholine challenge tests implemented in a stepwise fashion. Spirometry was performed by a trained technician using a regularly calibrated spirometer. Reversible airflow obstruction was defined as a $\geq 12 \%$ increase in forced expiratory volume in $1 \mathrm{~s}\left(\mathrm{FEV}_{1}\right) 15 \mathrm{~min}$ after administration of $200 \mu \mathrm{g}$ of salbutamol via pressurised metered 


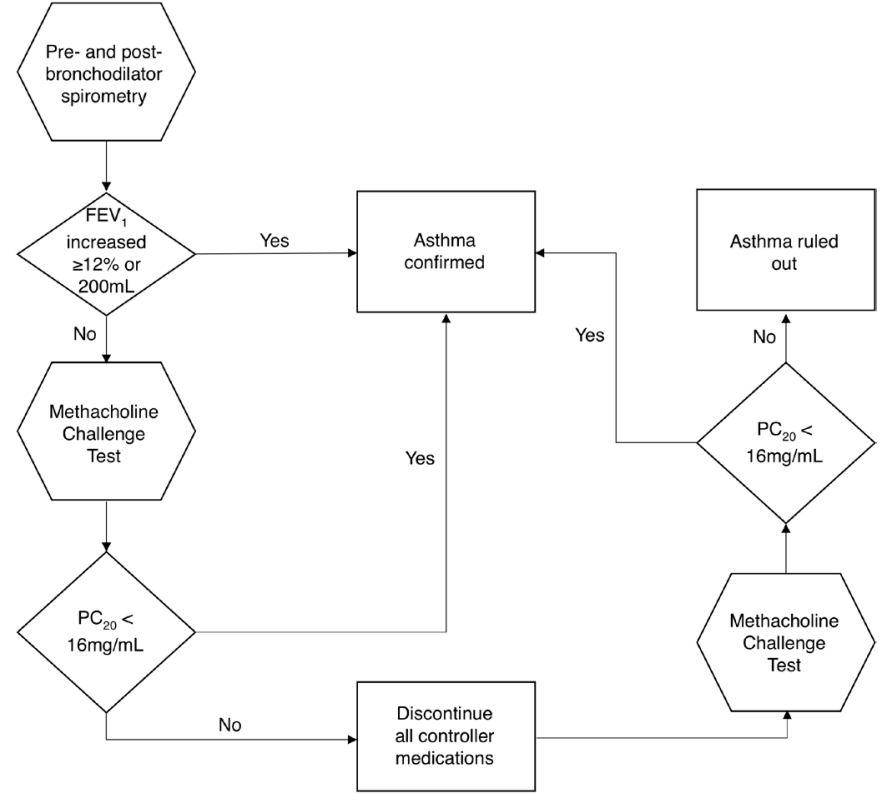

Figure 1 Algorithm for confirming or ruling out a diagnosis of asthma. $\mathrm{FEV}_{1}$, forced expiratory volume in $1 \mathrm{~s} ; \mathrm{PC}_{20}$, provocative concentration of methacholine needed to produce a $20 \%$ fall in $\mathrm{FEV}_{1}$ from baseline.

dose inhaler and a spacer device. ${ }^{23}$ Participants who did not meet the criteria for reversible airflow obstruction returned within 1 week to undergo a methacholine challenge test. Participants who did not meet the criteria for asthma diagnosis at the first methacholine challenge test had their controller medications tapered and discontinued

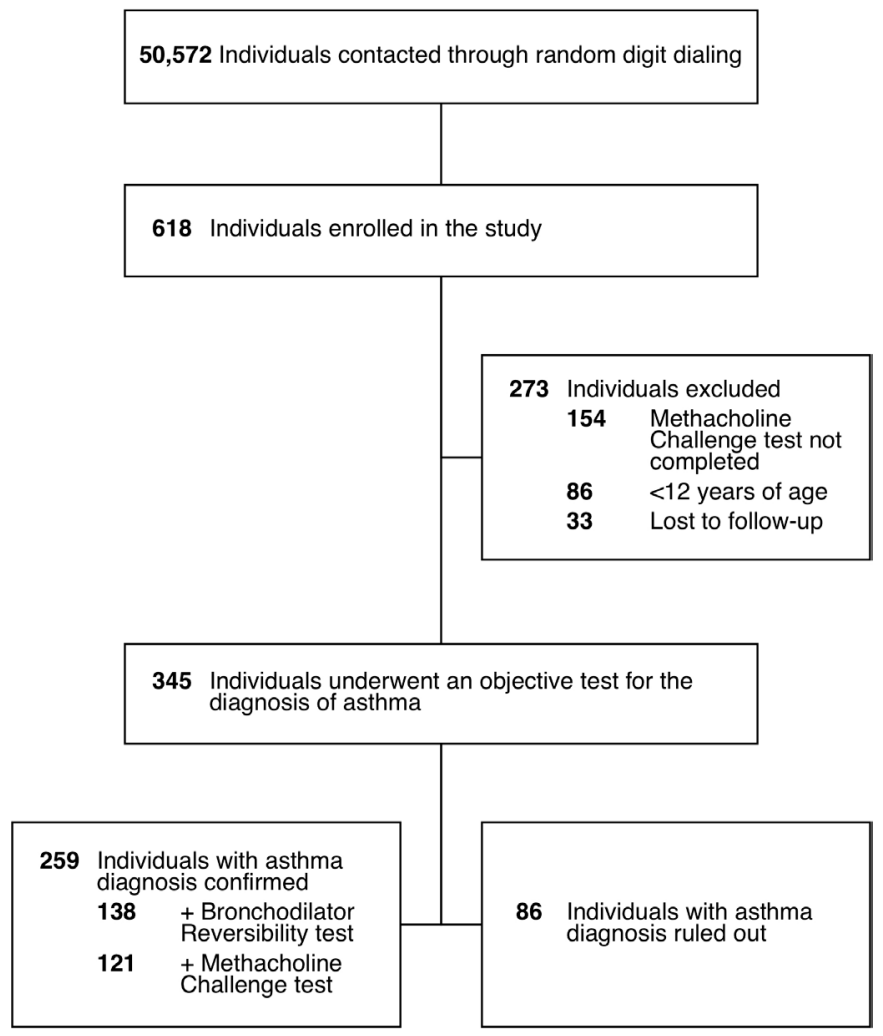

Figure 2 Sample selection procedure. by a respirologist before returning for a second methacholine challenge test. A diagnosis of asthma was ruled out if $\mathrm{FEV}_{1}$ decreased by $<20 \%$ following the administration of $16 \mathrm{mg} / \mathrm{mL}$ of methacholine ${ }^{24}$ in both methacholine challenge tests. Participants had a 'confirmed asthma diagnosis' if they met the criteria for asthma at the bronchodilator reversibility test or either methacholine challenge test.

\section{Statistical analysis}

All statistical analyses were performed in R V.3.5.0. ${ }^{25}$ We considered a two-tailed $\mathrm{p}$ value of $<0.05$ as statistically significant.

We constructed separate generalised linear regression models (negative binomial distribution, log link) for the primary and secondary outcomes. This resulted in five separate models for the following outcomes: annual asthmarelated (1) direct healthcare costs, (2) number of primary care physician visits, (3) number of specialist physician visits, (4) controller MPR and (5) reliever MPR. All models included the objective diagnosis of asthma (confirmed vs ruled out) as the exposure. Costs and MPR values (as a percentage) were rounded to the nearest integer value. Measured variables that have previously been shown to impact resource use were included as covariates in all models. ${ }^{1826}$ Models were adjusted for participants' tobacco smoking history (ever smoked vs never smoked), ethnicity (Caucasian vs non-Caucasian), age, sex, education (postsecondary vs no postsecondary), income (annual household income $\geq \$ \mathrm{C} 70000$ vs less) and third-party insurance coverage for medications (coverage vs no), all self-reported at baseline with a 12-month recall period. The resulting regression coefficients were exponentiated to create effect estimates on the relative scale (rate ratio). We did not adjust for asthma severity due to the high likelihood that there is a causal relationship between severe asthma and a confirmed diagnosis of asthma. ${ }^{12}$

\section{Patient and public involvement}

This study was based on secondary analysis of a cohort study; patients were not directly involved in its design or completion.

\section{RESULTS}

\section{Sample characteristics}

The cohort selection procedure is illustrated in figure 2. From the Economic Burden of Asthma cohort (618 participants), we excluded 86 participants who were $<12$ years of age, 154 in whom a methacholine challenge was contraindicated $(n=29)$, refused $(n=112)$ or could not be completed for other reasons $(n=13)$, and 33 participants who were lost to follow-up. The final study cohort included 345 participants, who underwent an objective diagnostic test for asthma at the final visit (12 months after baseline). The characteristics of participants in our study cohort are shown in table 1 . The characteristics of participants excluded from our study cohort are shown in online supplementary table E2. Of the participants, 212 
Table 1 Sample characteristics

\begin{tabular}{|c|c|c|c|c|}
\hline Characteristics & $\begin{array}{l}\text { Total } \\
(\mathrm{N}=345)\end{array}$ & $\begin{array}{l}\text { Asthma } \\
\text { confirmed } \\
(\mathrm{n}=259)\end{array}$ & $\begin{array}{l}\text { Asthma ruled out } \\
(\mathrm{n}=86)\end{array}$ & $\mathrm{P}$ value $\dagger$ \\
\hline \multicolumn{5}{|l|}{ Variables evaluated at baseline } \\
\hline Female, n (\%) & $212(61.4)$ & $156(60.2)$ & $56(65.1)$ & 0.50 \\
\hline Age, mean (SD) & $48.9(17.8)$ & $49.3(18.1)$ & $47.7(17.2)$ & 0.46 \\
\hline Ever smoked (vs never smoked), n (\%) & $93(27.0)$ & $71(27.4)$ & $22(25.6)$ & 0.85 \\
\hline Caucasian (vs non-Caucasian), n (\%) & $267(77.4)$ & $206(79.5)$ & $61(70.9)$ & 0.13 \\
\hline High income (vs low income) $\ddagger, n(\%)$ & $183(53.0)$ & $137(52.9)$ & $46(53.5)$ & $>0.99$ \\
\hline $\begin{array}{l}\text { Health insurance (full coverage vs not full coverage)§, } n \\
(\%)\end{array}$ & $69(20.0)$ & $52(20.1)$ & $17(19.8)$ & $>0.99$ \\
\hline $\begin{array}{l}\text { Higher education (postsecondary vs no postsecondary), } \\
\mathrm{n}(\%)\end{array}$ & $242(70.1)$ & $178(68.7)$ & $64(74.4)$ & 0.39 \\
\hline \multicolumn{5}{|l|}{ Variables evaluated during follow-up } \\
\hline $\begin{array}{l}\text { Total direct healthcare costs }(\$ C) \text {, mean }(\mathrm{SD}) \text {; median } \\
\text { (IQR) }\end{array}$ & $\begin{array}{l}450.5(629.2) \\
208.3(51.3-622.9)\end{array}$ & $\begin{array}{l}497.9(677.9) ; \\
237.6(68.7-694.1)\end{array}$ & $\begin{array}{l}307.7(424.1) \\
148.5(44.7-369.0)\end{array}$ & $<0.01^{*}$ \\
\hline Primary care physician visits, mean (SD) & $2.2(4.1)$ & $2.1(2.8)$ & $2.7(6.6)$ & 0.39 \\
\hline Specialist physician visits, mean (SD) & $0.5(1.9)$ & $0.6(2.2)$ & $0.2(0.8)$ & 0.16 \\
\hline MPR of controller medications, mean (SD) & $69.7 \%(74.4)$ & $74.9 \%(76.4)$ & $54.0 \%(65.8)$ & $<0.01^{*}$ \\
\hline MPR of reliever medications, mean (SD) & $28.4 \%(33.2)$ & $31.3 \%(34.3)$ & $19.5 \%(28.0)$ & $<0.01^{*}$ \\
\hline
\end{tabular}

*Significant at 0.05 level.

†P values for the absolute difference between the 'asthma confirmed' and 'asthma ruled out' groups were determined using a Mann-Whitney $\mathrm{U}$ test for continuous variables, with the exception of a Student $\mathrm{t}$-test for age, and Chi-squared test for categorical variables.

†High income defined as household income $\geq \$ C 70,000$.

§Full coverage defined as all drug and physician services paid for through third-party coverage.

MPR, medication possession ratio.

$(61.4 \%)$ were female, and the mean age at baseline was 48.9 (SD 17.8) years. A diagnosis of asthma was confirmed in $259(75.1 \%)$ participants: $138(53.3 \%)$ by bronchodilator reversibility test, $98(37.8 \%)$ following the first methacholine challenge test and 23 (8.9\%) following the second methacholine challenge test. Asthma was ruled out in $86(24.9 \%)$ participants following negative results on all bronchodilator reversibility and methacholine challenge tests.

\section{Total direct healthcare costs}

The average annual direct healthcare costs over 1 year was \$C497.9 (SD \$C677.9) in participants with confirmed asthma and \$C307.7 (SD \$C424.1) in those with asthma ruled out. There was a significant difference in average annual direct healthcare costs (\$C190.2) between exposure groups in the unadjusted analysis $(\mathrm{p}<0.01$; table 1$)$. The average annual direct healthcare cost was 1.6 times (95\% CI 1.14 to $2.22, \mathrm{p}<0.01$ ) higher in participants with confirmed asthma after adjustment for participants' smoking history, ethnicity, age, sex, education, income and insurance coverage (figure 3). Medications comprised the greatest proportion of total costs in both correctly diagnosed and overdiagnosed individuals (56.4\% and $47.6 \%$, respectively; table 2 ).

\section{Outpatient physician visits}

The total number of annual primary care and specialist physician visits was similar between participants with confirmed asthma and those with asthma ruled out (2.1 vs 2.7 primary care visits, $\mathrm{p}=0.39$; and 0.6 vs 0.2 specialist visits per year, $\mathrm{p}=0.16$; table 1 ). The adjusted analysis also indicated no significant difference in the number of primary care physician visits between participants with confirmed asthma and those with asthma ruled out ( $\mathrm{p}=0.10$; figure 3 ). However, confirmed asthma was associated with 2.41 times (95\% CI 1.05 to $5.40, \mathrm{p}=0.03$ ) more specialist visits than when an asthma diagnosis could be ruled out.

\section{Medication usage}

Participants with a confirmed diagnosis of asthma used controller medications for a greater proportion of follow-up time than those with asthma ruled out (MPR of $74.9 \%$ vs $54.0 \%, \mathrm{p}<0.01)$ and similarly for reliever medications ( $31.3 \%$ vs $19.5 \%, \mathrm{p}<0.01$; table 1$)$. This difference persisted in the adjusted analysis for reliever medications but not for controller medications $(\mathrm{p}=0.11$; figure 3$)$. The MPR for reliever medications was 1.62 times higher (95\% CI 1.09 to $2.35, \mathrm{p}=0.01$ ) among participants with confirmed asthma than those with asthma ruled out. 

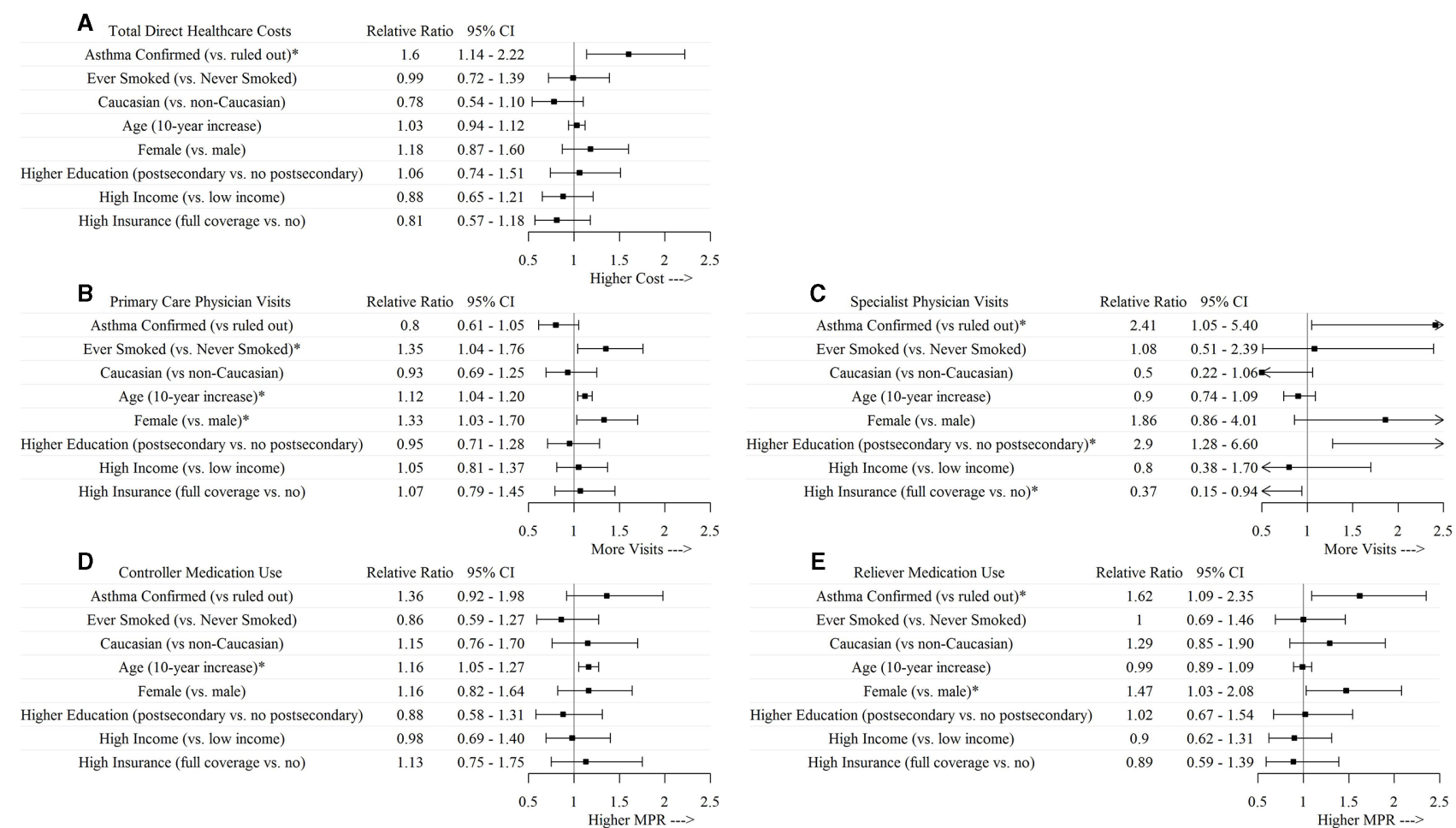

Figure 3 Relative ratios for the adjusted differences in asthma-related (A) total direct healthcare costs, (B) primary care physician visits, (C) specialist physician visits, (D) controller medication use, and (E) reliever medication use over 1 year of follow-up between patients with confirmed asthma and those with asthma ruled out. *Significant at 0.05 level. MPR, medication possession ratio.

\section{DISCUSSION}

In this study, we used objective testing to confirm the diagnosis of asthma in a population-based sample of patients with a self-reported physician diagnosis of asthma. We found that asthma could be ruled out in $25 \%$ of cases after negative spirometry and two negative methacholine challenge tests. This proportion is in line with the $28 \%-33 \%$ rate of overdiagnosis reported in previous Canadian studies. ${ }^{12} 1427$ We compared asthmarelated direct healthcare costs between participants with confirmed asthma versus those with asthma ruled out. Although total direct costs were higher in participants with a confirmed diagnosis of asthma, the costs of overdiagnosed asthma remained substantial. The average direct asthma-related healthcare costs for a participant with overdiagnosed asthma was \$C308 over 12 months, which was $\$$ C190 lower than for participants with a confirmed diagnosis. This difference in costs remained statistically significant after controlling for confounding variables that could affect both the exposure and outcomes but are likely not on the causal pathway between them.

Participants with overdiagnosed asthma visited specialists less frequently than those with confirmed asthma, but they visited primary care physicians as frequently. These participants may have scheduled a similar number of annual primary care visits for routine monitoring of 'asthma' activity or to fill new prescriptions. Conversely, participants with confirmed asthma may have had exacerbations of their asthma symptoms that required referral to a specialist physician to improve asthma control. ${ }^{28}$ Across both groups, participants visited primary care physicians more frequently than specialist physicians; $79 \%$ of our sample visited a primary care physician at least once during follow-up. The high frequency of these visits, and their low cost compared with specialist consultations, ${ }^{14}$ suggests that primary care visits may provide effective opportunities for re-evaluating previous asthma diagnoses.

On average, overdiagnosed participants possessed controller medications for over half of follow-up time and reliever medications for $20 \%$ of follow-up time. Reliever medications are typically used as needed, while controller medications are used daily. ${ }^{26}$ In comparison with participants with confirmed asthma, and after adjusting for potential confounders, participants with asthma ruled out tended to use similar levels of controller medications and less reliever medications. This difference may be due to a lower symptom burden in overdiagnosed participants, which led to self-adjustment of reliever medication use. ${ }^{29}$ Conversely, overdiagnosed individuals may have used controller medications as prescribed. However, previous studies have reported lower frequencies of controller medication use in patients with overdiagnosed asthma. ${ }^{1230}$

Although inhaled medications for asthma are generally safe, the use of asthma medications among overdiagnosed patients puts them at risk of net harm due to medication side effects. ${ }^{31}$ These patients are also incurring additional healthcare expenditure without therapeutic benefit. Further, asthma medications may have masked symptoms 
Table 2 Asthma-related healthcare cost categories over 1 year of follow-up

\begin{tabular}{|c|c|c|}
\hline Cost category & $\begin{array}{l}\text { Cost per patient } \\
\text { (\$C), mean (SD); } \\
\text { median (IQR) }\end{array}$ & $\begin{array}{l}\text { Percentage } \\
\text { of total cost } \\
\text { per patient* }\end{array}$ \\
\hline & Asthma ruled out & \\
\hline Medications & $\begin{array}{l}146.4(239.9) ; 28.2 \\
(2.2-203.2)\end{array}$ & 47.6 \\
\hline $\begin{array}{l}\text { Primary care physician } \\
\text { visits }\end{array}$ & $\begin{array}{l}118.2(292.6) ; 44.2 \\
(0-88.4)\end{array}$ & 38.4 \\
\hline $\begin{array}{l}\text { Specialist physician } \\
\text { visits }\end{array}$ & $27.9(101.4) \dagger$ & 9.1 \\
\hline Hospitalisations & $0(0) \dagger$ & 0.0 \\
\hline Emergency visits & $15.2(69.1) \dagger$ & 4.9 \\
\hline \multirow[t]{2}{*}{ Total } & $\begin{array}{l}307.7 \text { (424.1); } 148.5 \\
(44.7-369.0)\end{array}$ & 100.0 \\
\hline & Asthma confirmed & \\
\hline Medications & $\begin{array}{l}280.7 \text { (404.2); } 92.6 \\
(10.0-447.3)\end{array}$ & 56.4 \\
\hline $\begin{array}{l}\text { Primary care physician } \\
\text { visits }\end{array}$ & $\begin{array}{l}91.0(125.7) ; 44.2 \\
(44.2-132.6)\end{array}$ & 18.3 \\
\hline $\begin{array}{l}\text { Specialist physician } \\
\text { visits }\end{array}$ & $73.1(257.6) \dagger$ & 14.7 \\
\hline Hospitalisations & $39.2(362.6) \dagger$ & 7.9 \\
\hline Emergency visits & $13.9(72.1) \dagger$ & 2.8 \\
\hline Total & $\begin{array}{l}497.9 \text { (677.9); } 237.6 \\
(68.7-694.1)\end{array}$ & 100.0 \\
\hline
\end{tabular}

${ }^{*}$ Calculated using mean cost.

†The median cost is \$CO (IQR \$CO-\$CO).

of a serious underlying illness and resulted in a delay in the diagnosis and treatment of the correct disease. We did not evaluate the true underlying condition in this sample, but a similar study by Aaron $e t a l^{12}$ found that 2 out of 213 patients had subglottic stenosis, which was treated as asthma for a number of years before the correct diagnosis was identified during the study. If other health conditions were responsible for the overdiagnosis of asthma, their costs have implications for the burden of overdiagnosed asthma. For example, if ruling out an asthma diagnosis results in the correct alternative diagnosis, the proper management of the underlying condition could confer further cost benefits.

To our knowledge, this is the first study to examine the costs associated with overdiagnosed asthma. Our findings have important population-level implications. Given an estimate of approximately 785000 individuals with overdiagnosed asthma in Canada ${ }^{14}$ and an annual direct healthcare cost of \$C308 per patient, the estimated cost of overdiagnosed asthma in Canada is \$C242 million per year (2017 Canadian dollars). A previous study reported an average cost of \$C263 per patient (2009 Canadian dollars) for additional physician visits to reassess an asthma diagnosis. This resulted in an average lifetime cost savings of $\$ \mathrm{C} 351$ per patient screened, ${ }^{14}$ primarily due to the avoided costs of asthma medications. Our results suggest that additional screening to correct an overdiagnosis of asthma would save asthma-related costs in the first year, with savings compounding in subsequent years. Savings could be reallocated to the management of individuals with a true diagnosis of asthma, especially those with severe asthma who could pursue novel but expensive treatments, or to identify and treat the underlying diseases of overdiagnosed patients. ${ }^{32}$ Given the prevalence and costs of overdiagnosis, our findings highlight the need for routine objective testing to confirm all new and existing diagnoses of asthma. ${ }^{26}$

There are several strengths to this study. We used a population-based random sample of patients with a physician diagnosis of asthma, meaning our results are likely to be representative of routine healthcare use in the general asthma population. We used longitudinal healthcare utilisation data, which, compared with cross-sectional data, are likely to provide a less biased estimate of the average costs accrued by an individual. Finally, we evaluated airway reversibility using objective testing following the recommendations of international guidelines. ${ }^{26}$ This allowed us to evaluate the costs of evidence-based best practices.

Our study has several limitations. We did not include indirect costs in our analysis, and we were therefore unable to consider the societal costs of overdiagnosis. Previous studies suggest that the cost of productivity loss in this sample is substantial. ${ }^{16}$ Further, our use of the lowest price equivalent for medication cost may only be applicable to publicly funded healthcare systems. Physician visits and medication use were self-reported with a recall period of 3 months. It is possible that recall bias reduced the accuracy of our measurements. Our algorithm for ruling out asthma involved one less methacholine challenge test than in some previous studies, ${ }^{12} 1430$ which makes it slightly less rigorous. It is possible that this led to a higher rate of overdiagnosis in our study; however, over $90 \%$ of diagnoses were confirmed by the second visit in previous studies. ${ }^{14}{ }^{27}$ In contrast, our estimates of overdiagnosis may be conservative due to the likelihood of false positive methacholine challenge tests ${ }^{24}$; this in turn may have resulted in an underestimation of cost. We excluded participants in whom an objective diagnostic test was contraindicated due to asthma-related reasons, which may have resulted in lower representation of participants with more severe disease and therefore higher resource utilisation. Finally, we only assessed asthma-related costs; we were unable to determine the costs of the true underlying condition or the benefit of correcting the diagnosis.

\section{CONCLUSIONS}

In this population-based sample, one in four participants with a physician diagnosis of asthma had their diagnosis ruled out on objective airflow reversibility testing. Patients with overdiagnosed asthma consumed a substantial amount of asthma-related healthcare resources, although less than those with confirmed asthma. The extent of 
overdiagnosed asthma in Canada and other countries, and its associated healthcare resource costs, suggests that the population-level burden of overdiagnosed asthma is high. Future studies should evaluate the cost-effectiveness of systematic screening or case detection initiatives for re-evaluating previous diagnoses of asthma.

Acknowledgements We would like to thank all members of the Economic Burden of Asthma study team.

Contributors JMF and MS conceived, designed and conducted the Economic Burden of Asthma study. MS formulated the current study idea, and MS, KMJ and BN designed the study. BN performed all data analyses and wrote the first draft of the manuscript. AS and KMJ provided guidance on the statistical analysis. All authors critically commented on the manuscript and approved the final version. $\mathrm{KMJ}$ is the guarantor of the manuscript.

Funding This study was funded by Collaborative Innovative Research Fund, an arm's-length, investigator-initiated, peer-reviewed grant from GSK Canada. The funders had no role in study design, data collection and analysis, or preparation of the manuscript.

Competing interests BN, AS, JMF and KMJ have no conflicts to declare. MS has received honorarium for unrelated consultancy work from GSK Canada and GSK Global.

Patient consent for publication Not required.

Ethics approval The Economic Burden of Asthma study received approval from the University of British Columbia Human Ethics Board (\#H10-01542).

Provenance and peer review Not commissioned; externally peer reviewed.

Data availability statement Data are available in a public, open access repository.

Open access This is an open access article distributed in accordance with the Creative Commons Attribution Non Commercial (CC BY-NC 4.0) license, which permits others to distribute, remix, adapt, build upon this work non-commercially, and license their derivative works on different terms, provided the original work is properly cited, appropriate credit is given, any changes made indicated, and the use is non-commercial. See: http://creativecommons.org/licenses/by-nc/4.0/.

\section{ORCID iD}

Kate M Johnson http://orcid.org/0000-0001-7406-2448

\section{REFERENCES}

1 Braman SS. The global burden of asthma. Chest 2006;130:4S-12.

2 Global Initiative for Asthma (GINA). Global strategy for asthma management and prevention, 2018. Available: https://ginasthma. org/2018-gina-report-global-strategy-for-asthma-management-andprevention [Accessed 23 Aug 2018].

3 FitzGerald JM. Editorial: targeting lung attacks. Thorax 2011;66:365-6.

4 Bousquet J, Bousquet PJ, Godard P, et al. The public health implications of asthma. Bull World Health Organ 2005;83:548-54.

5 Chen W, Lynd LD, FitzGerald JM, et al. Excess medical costs in patients with asthma and the role of comorbidity. Eur Respir J 2016;48:1584-92.

6 National Institutes of health. expert panel report 3: guidelines for the diagnosis and management of asthma full report 2007. Natl Hear Lung, Blood Inst 2007.

7 Jin R, Choi BC, Chan BT, et al. Physician asthma management practices in Canada. Can Respir J 2000;7:456-65.

8 Sharpe H, Sin D, Andrews E, et al. Alberta strategy to help manage asthma (asthma): a provincial initiative to improve outcomes for individuals with asthma. Healthc Q 2004;7:55-60.

9 Gershon AS, Victor JC, Guan J, et al. Pulmonary function testing in the diagnosis of asthma: a population study. Chest 2012;141:1190-6.
10 Sokol KC, Sharma G, Lin Y-L, et al. Choosing wisely: adherence by physicians to recommended use of spirometry in the diagnosis and management of adult asthma. Am J Med 2015;128:502-8.

11 Heffler E, Crimi C, Mancuso S, et al. Misdiagnosis of asthma and COPD and underuse of spirometry in primary care unselected patients. Respir Med 2018;142:48-52.

12 Aaron SD, Vandemheen KL, FitzGerald JM, et al. Reevaluation of diagnosis in adults with physician-diagnosed asthma. JAMA 2017;317:269-79.

13 Aaron SD, Boulet LP, Reddel HK, et al. Underdiagnosis and overdiagnosis of asthma. Am J Respir Crit Care Med 2018;198:1012-20.

14 Pakhale S, Sumner A, Coyle D, et al. (correcting) misdiagnoses of asthma: a cost effectiveness analysis. BMC Pulm Med 2011;11:27.

15 Chen W, FitzGerald JM, Rousseau R, et al. Complementary and alternative asthma treatments and their association with asthma control: a population-based study. BMJ Open 2013;3:e003360.10.1136/bmjopen-2013-003360

16 Sadatsafavi M, Rousseau R, Chen W, et al. The preventable burden of productivity loss due to suboptimal asthma control. Chest 2014;145:787-93.

17 British Columbia Statistics. Open Data from the Census - BC Stats. Census Div. Regional Dist. Census Subdiv. Municipalities, RDEAs, Indian Reserv, 2011. Available: http://www.bcstats.gov.bc. ca/StatisticsBySubject/Census/OpenData.aspx [Accessed 15 May 2018].

18 Sadatsafavi M, Chen W, Tavakoli H, et al. Saving in medical costs by achieving guideline-based asthma symptom control: a populationbased study. Allergy Eur J Allergy Clin Immunol 2016.

19 Bedouch P, Sadatsafavi M, Marra CA, FitzGerald JM, et al. Trends in asthma-related direct medical costs from 2002 to 2007 in British Columbia, Canada: a population based-cohort study. PLoS One 2012;7:e50949.

20 British Columbia Ministry of Health. PharmaCare Downloadable data file, 2013. Available: https://www2.gov.bc.ca/gov/content/health/ practitioner-professional-resources/pharmacare/health-industryprofessionals/downloadable-drug-data-files [Accessed 19 Jul 2018].

21 Statistics Canada. Table 18-10-0005-01 consumer price index, annual average, not seasonally adjusted, 2018. Available: https:// www150.statcan.gc.ca/t1/tbl1/en/tv.action?pid=1810000501

22 Andrade SE, Kahler KH, Frech F, et al. Methods for evaluation of medication adherence and persistence using automated databases. Pharmacoepidemiol Drug Saf 2006;15:565-74.

23 Boulet LP, Becker A, Berube D, et al. Canadian asthma consensus report, 1999. Canadian asthma consensus group. CMAJ 1999;161:S1-61.

24 Guidelines for methacholine and exercise challenge Testing-1999. Am J Respir Crit Care Med 2000;161:309-29.

25 R Core Team. R: a language and environment for statistical computing 2018.

26 Sullivan PW, Ghushchyan VH, Slejko JF, et al. The burden of adult asthma in the United States: evidence from the medical expenditure panel survey. J Allergy Clin Immunol 2011;127:363-9.

27 Luks VP, Vandemheen KL, Aaron SD. Confirmation of asthma in an era of overdiagnosis. Eur Respir J 2010;36:255-60.

28 Schatz M, Rachelefsky G, Krishnan JA. Follow-Up after acute asthma episodes: what improves future outcomes? Proc Am Thorac Soc 2009;6:386-93.

29 Horne R, Weinman J, Self-regulation WJ. Self-Regulation and selfmanagement in asthma: exploring the role of illness perceptions and treatment beliefs in explaining Non-adherence to preventer medication. Psychol Health 2002;17:17-32.

30 Aaron SD, Vandemheen KL, Boulet L-P, et al. Overdiagnosis of asthma in obese and nonobese adults. Can Med Assoc $J$ 2008;179:1121-31.

31 Lipworth BJ. Systemic adverse effects of inhaled corticosteroid therapy: a systematic review and meta-analysis. Arch Intern Med 1999;159:941-55.

32 Corrigan SP, Cecillon DL, Sin DD, et al. The costs of implementing the 1999 Canadian asthma consensus guidelines recommendation of asthma education and spirometry for the family physician. Can Respir J 2004;11:349-53. 